\title{
A Iniciação Científica como experiência para a escolha profissional
}

Alessandra Pereira Gomes Machado* Heloísa de Andrade Rodrigues Santos ${ }^{* *}$

\section{Resumo:}

A avaliação diagnóstica da fluência em leitura oral é realizada por meio da análise de processos da leitura em voz alta baseado no modelo de leitura desenvolvido por Machado (2018). No projeto de Iniciação Científica do Colégio de Aplicação da Universidade Federal de Sergipe (Codap/UFS) por meio do Programa Institucional de Bolsas de Iniciação Científica no Ensino Médio (PIBIC-EM), as atividades desenvolvidas atendem à proposta de realizar a edição, a codificação e a transcrição ortográfica dos áudios da leitura em voz alta dos estudantes do 6 o ano do Codap/UFS. Este relato de experiência tem o objetivo de mostrar a relação entre a participação neste projeto e a escolha profissional da discente de Iniciação Científica do Ensino Médio. Com o envolvimento na pesquisa, a discente relata as contribuições para a formação acadêmica e para o novo olhar para o estudo da Língua Portuguesa.

\section{Palavras-chave:}

PIBIC-EM. Leitura em voz alta. Experiência profissional.

\begin{abstract}
:
The diagnostic assessment of oral reading fluency is performed by analyzing the processes of reading aloud based on the reading model developed by Machado (2018). In the scientific initiation project of the do Colégio de Aplicação da Universidade Federal de Sergipe (Codap/UFS) through the Institutional Program for Scientific Initiation Scholarships in High School (PIBIC-EM), the activities developed meet the proposal to execute the edition, the coding and orthographic transcription of the audios of reading aloud to 6 th grade students at Codap / UFS. This experience report objective to show the relationship between participation in this project and the professional choice of high school scientific initiation students. With the involvement in the research, the student reports the contributions for the academic formation and for the new look for the study of the Portuguese Language.
\end{abstract}

\section{Keywords:}

PIBIC-EM. Reading aloud. Professional experience.

\footnotetext{
* Doutora em Educação, professora de Língua Portuguesa do Colégio de Aplicação da Universidade Federal de Sergipe. E-mail: alessandrasje@hotmail.com. ORCID iD: http://orcid.org/0000-0003-2351-6299.

** Estudante do 2o ano do Ensino Médio do Colégio de Aplicação da UFS, bolsista voluntária de Iniciação Científica (PIBIC-EM). E-mail: heloisapo@outlook.com.
} 


\section{Introdução: uma estudante do Ensino Médio e a Iniciação Científica}

Sou ${ }^{1}$ estudante do Colégio de Aplicação da Universidade Federal de Sergipe (Codap/UFS), desde 2015, quando entrei no $6^{\circ}$ ano do Ensino Fundamental, por sorteio público de vagas. Desde então, o colégio tem me proporcionado muitas oportunidades de aprendizagem, de pesquisa e de atividades de extensão. Diversas experiências para agregar ao conhecimento, sejam elas curriculares ou extracurrilares, dentre elas está o Programa Institucional de Bolsas de Iniciação Científica no Ensino Médio (PIBIC-EM).

O PIBIC-EM que é oferecido nas escolas públicas do Brasil tem como objetivo ingressar o aluno no campo das pesquisas científicas para ampliar o desenvolvimento do conhecimento, despertar a aptidão dos estudantes para futuras áreas de atuação, desenvolver o pensamento crítico e capacitar o estudante para processos necessários na educação científica.

O projeto de que participo, "Avaliação diagnóstica de estudantes da educação básica: fluência em leitura oral e compreensão leitora", orientado pela Profa. Dra. Alessandra Machado, tem como objetivo realizar acompanhamento longitudinal de estudantes do $6^{\circ}$ ano de 2019 do Codap/UFS, fazer avaliação de fluência em leitura oral a partir da coleta de leitura em voz alta dos estudantes participantes e contribuir para a prática da avaliação diagnóstica da fluência em leitura oral. Neste projeto, que abarca estudantes da graduação e da educação básica, minhas atividades de Iniciação Científica do PIBIC-EM se inserem no plano de trabalho Transcrição ortográfica da leitura em voz alta.

O objetivo deste texto é relatar a minha experiência com a Iniciação Científica e as contribuições para minha escolha profissional.

\section{A Iniciação Científica: os procedimentos metodológicos e a minha escolha profissional}

Em dezembro de 2019, ingressei nesse projeto de Iniciação Científica (IC) que já estava em andamento. Um colega me avisou da vaga para bolsista voluntária, porque sabia da minha orientação profissional.

Quando conversei com a professora sobre a temática do projeto, não entendia sobre avaliação diagnóstica nem fluência em leitura oral, mas gostei de saber que iríamos trabalhar com leitura. À medida que participava das reuniões, comecei a me inteirar dos procedimentos metodológicos da pesquisa. Estas reuniões eram realizadas juntamente com os orientandos de IC da graduação, o que me proporcionava um contato maior com os graduandos e com as discussões sobre o projeto. A minha orientadora é professora de Língua Portuguesa do Codap e todos os outros que participam do projeto cursam Licenciatura em Letras Vernáculas ou Letras e uma língua estrangeira. Isto também me interessava muito e mais adiante falaremos sobre a minha escolha profissional, que é Licenciatura em Letras, como a deles.

Os procedimentos metodológicos para avaliação da fluência em leitura oral seguem o estabelecido em Machado (2018) que consistem em: seleção de textos adequados à escolaridade do estudante, formatação desses textos para a realização da atividade de leitura em voz alta e gravação da leitura em voz alta dos estudantes do $6^{\circ}$ ano, ano letivo de 2019 (final do ano) e 2020 (início do ano), de forma individual em uma sala de aula reservada. A avaliação diagnóstica é realizada considerando a leitura em voz alta de um texto, seguindo o protocolo do método Curriculum-Based Measurement (CBM), que prevê a aferição de 1 minuto de leitura. Os dados de leitura coletados são editados, codificados e analisados, considerando os parâmetros de fluência em leitura oral: velocidade, precisão, prosódia e atendendo ao modelo de leitura (MACHADO, 2018).

Minhas atividades no projeto se inserem na edição, codificação e transcrição dos dados de leitura que são os áudios da leitura em voz alta dos estudantes do $6^{\circ}$ ano do Codap/UFS. Assim, o plano de trabalho

1. O artigo é um relato escrito em primeira pessoa pela estudante Heloísa Santos sob orientação de Alessandra Machado. 
do projeto de IC de que estou participando atende ao objetivo de instrumentalizar para o uso especializado dos softwares Audacity e ELAN para realizar a edição e a transcrição desses áudios (OUSHIRO, 2014) da leitura em voz alta.

A minha orientadora já havia me explicado essa parte quando entrei no projeto, mas eu não fazia ideia de como iria desenvolver essas atividades. Em uma de nossas reuniões, ela apresentou esses softwares que seriam utilizados na edição dos dados e organizou um curso de extensão sobre o ELAN para que todos os orientandos pudessem fazer para compreender os procedimentos de uso.

Em março de 2020, participei da coleta de leitura em voz alta dos estudantes do $6^{\circ}$ ano de 2020 , as leituras foram realizadas de forma individual e em ambiente controlado, ou seja, um estudante por vez, em sala de aula previamente reservada. Tentamos construir um ambiente tranquilo para os estudantes para que não houvesse alterações nos áudios e que o nervosismo não atrapalhasse o desempenho do estudante durante a leitura em voz alta. Alguns chegaram a pensar que a leitura teria alguma pontuação, mas tudo foi devidamente explicado.

Com os dados de pesquisa em mãos, passei a trabalhar com a edição dos áudios no software Audacity para atender a 1 minuto de leitura. Mesmo que a leitura em voz alta tenha durado mais de 1 minuto, para a análise o áudio é editado em 1 minuto no software Audacity. Também, realizei a codificação dos áudios. Cada estudante recebe um código que é indicado por: iniciais dos nomes em maiúsculo, seguidos por série e turma, sexo, mês e ano da coleta e número do texto lido, que é de acordo com o início ou final do ano letivo. Como exemplo temos: HARS-6B-F-03.20-T1. Essa primeira etapa foi bem tranquila.

Após essa etapa, realizei as transcrições ortográficas no software ELAN. Essa etapa, no entanto, exigiu muita dedicação e horas de audição dos áudios. Para a realização das transcrições, participei do curso de formação Transcrição de áudio no ELAN para fins acadêmicos, que foi organizado pela minha orientadora para que eu aprendesse a utilizar o software e todas as funções disponíveis para auxiliar no trabalho. As transcrições são realizadas para ajudar na análise dos processos de leitura que possibilita revisitar os dados várias vezes, no sentido de apurar as análises.

Na produção das transcrições, eu transcrevi os áudios de 1 minuto da leitura em voz alta dos estudantes do $6^{\circ}$ ano de 2020. Seguimos as normas para transcrição ortográfica adotadas pelo Banco de Dados Falares Sergipanos (MACHADO, 2018), conforme o Quadro 1:

Quadro 1 - Normas para transcrição

\begin{tabular}{|l|l|l|}
\hline Ocorrência & Símbolos & Exemplos \\
\hline Final de 1 minuto de leitura & ] & \\
\hline Pausas & $\ldots$ & Todos os dias... a menininha... estava lá \\
\hline Leitura silábica & - & pra-ci-nha \\
\hline Autocorreção & $/$ & menina/menininha \\
\hline Nomes próprios & Iniciais maiúsculas & chamava-se Eunice Vasconcelos \\
\hline Números & Por extenso & a década de vinte \\
\hline Incompreensão do que ouviu & $($ ) & \\
\hline Palavras não dicionarizadas & \{\} & griações, permanecente \\
\hline
\end{tabular}

Fonte: Machado (2018)

Participaram dessa pesquisa 40 estudantes do $6^{\circ}$ ano do Ensino Fundamental do Codap/UFS do ano letivo de 2020. Destes 19 são do sexo feminino e 21 do masculino.

Após as transcrições, os outros participantes do projeto de Iniciação Científica da graduação assumem as análises dos dados. As transcrições facilitam os processos de análise da fluência em leitura oral atendendo às dimensões de velocidade, prosódia e precisão da leitura em voz alta e os resultados são contabilizados para indicar pistas de automaticidade na decodificação que levam à compreensão leitora de cada estudante (MACHADO, 2018). 
O conceito de leitura abordado no projeto é o de automaticidade na leitura em voz alta que é a capacidade de identificação do sistema ortográfico, relação entre letras/grafemas e sons/fonemas, e os significados das palavras expressas no texto. A automaticidade na decodificação é o reconhecimento das pronúncias e dos significados das palavras escritas imediatamente ao vê-las, sem se dedicar atenção cognitiva ou esforço para decodificá-las (MACHADO, 2018). Sendo assim, a avaliação diagnóstica vai averiguar, entre os estudantes do $6^{\circ}$ ano do Codap/UFS, como está a automaticidade na decodificação da leitura em voz alta, se conseguem identificar o que está no texto e se a leitura é adequada ao que está escrito. Essa avaliação mostra se o leitor está tentando compreender o texto que está lendo ou se está apenas decifrando as letras sem intenção de compreender. A automaticidade na leitura do texto contribui para a compreensão leitora.

Essa perspectiva de leitura era algo novo para mim, até então só pensava na compreensão leitora e na formação crítica do jovem leitor.

\section{Palavras finais: a Iniciação Científica e a perspectiva profissional}

A participação no projeto de Iniciação Científica, além de contribuir para minha formação, também está me proporcionando a interação com estudantes da graduação em Letras. Com isso nós já podemos adentrar em um outro assunto: minha futura profissão. Foi um total e maravilhoso acaso a relação entre o projeto e a minha intenção em cursar Licenciatura em Letras. Começo a ter, mesmo que de maneira mais leve, um contanto com a língua muito diferenciado das minhas aulas de Língua Portuguesa no Codap/UFS e essa vivência, provavelmente, demoraria para acontecer.

Após os resultados obtidos sobre a compreensão leitora de cada estudante, a minha orientadora começa a trabalhar separadamente com os estudantes que têm necessidade de desenvolver a leitura. O projeto é, primordialmente, para ajudar os estudantes que possuem dificuldade na fluência em leitura em voz alta e em compreender aquilo que lê. Ter contanto com o projeto, alimenta em mim, ainda que precocemente, a ideia de ter um olhar cada vez mais humano sobre a maneira de exercer minha futura profissão. Esta pesquisa está me mostrando que é preciso respeitar as particularidades dos alunos e auxiliar no desenvolvimento de seus processos de aprendizagem.

O PIBIC-EM superou minhas expectativas em diversos sentidos, a participação nas reuniões, o compromisso com as atividades, a familiarização com um tema que nunca tinha discutido e o contato com o ELAN, tudo isso foi, satisfatoriamente, enriquecedor. E agora costumo pensar que a Iniciação Científica não é algo nem tão fácil ou difícil quanto parece, existem muitas coisas agregadas a ela, o direcionamento para estudar e fazer o projeto acontecer, a interação com assuntos distantes do meu cotidiano escolar e, por fim, uma realidade que me aproxima daquilo que provavelmente será minha graduação. Nunca vou esquecer do projeto do PIBIC-EM e quero um dia ter a oportunidade de realizar com meus futuros alunos.

\section{Referências}

MACHADO, Alessandra Pereira Gomes. Fluência em leitura oral e compreensão em leitura: automaticidade na decodificação para a compreensão leitora. 2018. Tese (Doutorado em Educação) - Universidade Federal de Sergipe, São Cristóvão, 2018.

OUSHIRO, Lívia. Transcrição de entrevistas sociolinguísticas com o ELAN. In: FREITAG, Raquel Meister Ko (org.). Metodologia de coleta e manipulação de dados em sociolinguística. São Paulo: Editora Edgard Blücher, 2014. p. 117-132.

Data de submissão: 19/06/2020

Data de aceite: $27 / 07 / 2020$ 